\title{
Mapeamento das produções relacionadas a Modelagem Matemática e deficiência intelectual: um olhar nas pesquisas recentes
}

Edmilson Ferreira Pereira Junior

Jurema Lindote Botelho Peixoto

\section{Resumo}

O presente artigo visa investigar de que maneira são apresentados os trabalhos que versam sobre a Modelagem Matemática como estratégia de ensino para pessoas com Deficiência Intelectual no contexto inclusivo. Para este estudo foi feito um levantamento a respeito da Educação Inclusiva no Brasil, em especial a Deficiência Intelectual e aspectos relacionados a Modelagem Matemática. Além disso, foi utilizado o mapeamento como método de pesquisa conforme preconiza Biembengut, para estudar os trabalhos consultados foram construídas categorias de análise para poder organizá-los. Como resultado encontrou-se alguns trabalhos que discutem algumas estratégias utilizadas para os alunos com Deficiência Intelectual nas aulas de matemática. É possível perceber que em alguns dos trabalhos a modelagem aparece de forma implícita, no entanto, não é descrita pelos autores dos trabalhos analisados.

Palavras-chaves: Educação Inclusiva. Deficiência Intelectual. Modelagem matemática. 


\title{
MAPPING OF PRODUCTS RELATED TO MATHEMATICAL MODELING AND INTELLECTUAL DISABILITY: A LOOK AT RECENT RESEARCH
}

"Edmilson Ferreira Pereira Junior"<edmilsonufrb@gmail.com>

"Jurema Lindote Botelho Peixoto"<jurema@uesc.br>

\begin{abstract}
This article aims to investigate how the works that deal with Mathematical Modeling as a teaching strategy for people with Intellectual Disabilities in the inclusive context are presented. For this study was made a survey about Inclusive Education in Brazil, especially the Intellectual Disability and aspects related to Mathematical Modeling. In addition, mapping was used as a research method as recommended by Biembengut, to study the consulted works were built categories of analysis to be able to organize them. As a result we found some papers that discuss some strategies used for students with Intellectual Disabilities in math classes. It is possible to notice that in some of the works the modeling appears implicitly, however, it is not described by the authors of the analyzed works.
\end{abstract}

Keywords: Inclusive Education. Intellectual disability. Mathematical modeling. 


\section{Introdução}

O presente trabalho teve como objetivo investigar de que maneira são apresentados os trabalhos relacionados à Modelagem Matemática como estratégia de ensino para pessoas com Deficiência Intelectual no contexto inclusivo. Foi tomado como fonte de pesquisa os trabalhos que foram publicados nos últimos cinco anos (2014 - 2018) no Banco de Teses e Dissertações da Coordenação de Aperfeiçoamento de Pessoal de Nível Superior (CAPES).

Foi utilizado como método nesse estudo o mapeamento para pesquisa educacional conforme Biembengut (2008), permitindo ao pesquisador melhor entendimento de ações pedagógicas. Como preconiza a autora, para se realizar um mapeamento é importante que seja entendido os objetos que pretende ser mapeados, as tendências, as formas que devem ser utilizados, os símbolos apontados, assim, poderão contribuir na facilitação da leitura do que se pretende buscar.

Na matemática, um dos principais problemas descritos pelos professores é em relação a falta de interesse dos alunos nas aulas e ausência de motivação. Além disso, o professor ainda tem que "competir" com as tecnologias digitais que estão presentes no cotidiano dos alunos. Quando se trata na Educação Matemática para o Público Alvo da Educação Especial - PAEE, é possível perceber que essa realidade ainda pode ser mais complicada, pois, existe pouca literatura voltada para o ensino de matemática para o PAEE.

Com a LDB/96 passa ser obrigatório a oferta de vagas para os alunos Público Alvo da Educação Especial - PAEE no ensino regular e apoio especializado, quando necessário, atendendo as particularidades de cada indivíduo por meio do Atendimento Educacional Especializado - AEE.

Desse modo, entende-se que os professores precisam estar preparados para obter condições de atender esses alunos em suas aulas. Por isso, é interessante se pensar em estratégias de ensino que possam contribuir no processo de ensino e aprendizagem pensando nos alunos PAEE. Neste contexto, insere-se a Modelagem na Educação - Modelação que é trazida por Bassanezi (2010, p. 16) "como a arte de transformar problemas da realidade em problemas matemáticos resolvê-los, interpretando suas soluções na linguagem do mundo real".

Assim, para direcionar essa pesquisa, apresenta-se a seguinte problemática: Como são apresentados os trabalhos relacionados a Modelagem Matemática como Estratégia de ensino para alunos com Deficiência Intelectual no contexto da inclusão?

Neste artigo apresenta-se a introdução em que informa ao leitor seu objetivo e questão de pesquisa. Na sequência é apresentado o aporte teórico trazendo um pouco da trajetória da educação inclusiva no Brasil limitando-se a Deficiência Intelectual, que foi o objeto de estudo e em seguida apresenta-se a Modelagem Matemática como estratégia de ensino. Nos aspectos metodológicos é exposto como ocorreu o percurso deste trabalho e, em seguida apresenta-se 
as discussões e resultados onde são descritas as percepções obtidas. E por fim, as considerações finais deste trabalho.

\section{Aporte teórico: Educação Inclusiva no Brasil}

A educação inclusiva no Brasil começou a ganhar dimensão a partir de 1990, por conta da Conferência Mundial de Educação para Todos que ocorreu em Jomtien, na Tailândia. Durante este evento, "o Brasil estabeleceu metas básicas para melhorar o sistema educacional brasileiro. Entre esses objetivos, parecia necessário melhorar a educação de crianças e adolescentes com necessidades especiais" (MENDES; ALMEIDA; TOYODA, 2011, p. 82).

Kassar (2011), nos aponta que a consolidação de políticas voltadas para educação inclusiva teve maior impacto no Brasil após a implementação da Constituição de 1988. Acreditamos que este possa ser um dos motivos pela participação do Brasil na Conferência Mundial de Educação para Todos, em 1990. A autora ainda afirma que foi nesta conferência que o Brasil firmou "a responsabilidade de assegurar a universalização do direito à Educação. Desse compromisso decorreu a elaboração do Plano Decenal de Educação para Todos, concluído em 1993” Kassar (2011, p. 70). O Plano Decenal de Educação para Todos, por sua vez, tinha como compromisso que:

...o governo brasileiro assume, de garantir a satisfação das necessidades básicas de educação de seu povo, expressam-se no PLANO DECENAL DE EDUCAÇÃO PARA TODOS, cujo objetivo mais amplo é assegurar, até o ano 2003, a crianças, jovens e adultos, conteúdos mínimos de aprendizagem que atendam a necessidades elementares da vida contemporânea (BRASIL, 1993, p. 13).

Diante deste compromisso traçado pelo governo brasileiro, Kassar (2011) afirma que as pessoas com deficiências são contempladas pela garantia de uma educação para todos. Porém, a autora ainda afirma que as propostas voltadas para as pessoas com deficiências possuem alguns elementos específicos que não estariam plenamente contemplados nesse documento.

Desse modo, Kassar (2011) destaca a realização de um evento que teve um marco bastante importante na educação especial no Brasil, a Conferência Mundial sobre Necessidades Educativas Especiais: acesso e qualidade, na Espanha em 1994. Em especial a Declaração de Salamanca. Neste documento, a autora destaca que "essa declaração enuncia que diante do alto custo em manter instituições especializadas as escolas comuns devem acolher todas as crianças independentes de suas condições físicas, intelectuais, sociais, emocionais, linguísticas ou outros” (KASSAR, 2011, p.71).

Após dois anos, com a Lei de Diretrizes e Bases da Educação Nacional em 1996 LDB/96 é proposto adequação das escolas para poder atender a todos os estudantes sem 
nenhuma distinção. Nela também é descrito a respeito da Educação Especial no Capítulo V, artigo 58 ao declarar que:

Art. 58. Entende-se por educação especial, para os efeitos desta Lei, a modalidade de educação escolar oferecida preferencialmente na rede regular de ensino, para educandos com deficiência, transtornos globais do desenvolvimento e altas habilidades ou superdotação.

$\S 1^{0}$ Haverá, quando necessário, serviços de apoio especializado, na escola regular, para atender as peculiaridades da clientela de educação especial.

$\S 2^{\circ} \mathrm{O}$ atendimento educacional será feito em classes, escolas ou serviços especializados, sempre que, em função das condições específicas dos alunos, não for possível a sua integração nas classes comuns de ensino regular.

$\S 3^{\circ}$ A oferta de educação especial, nos termos do caput deste artigo, tem início na educação infantil e estende-se ao longo da vida, observados o inciso III do art. $4^{\circ}$ e o parágrafo único do art. 60 desta Lei. (BRASIL, 1996)

Neste cenário, entende-se que com a LDB/96 passa ser obrigatória a oferta da educação para os alunos com necessidades especiais no ensino regular e apoio especializado, quando necessário, atendendo as particularidades de cada indivíduo por meio do Atendimento Educacional Especializado - AEE.

Diante destas discussões, tanto no Brasil, quando fora dele, iniciou-se as primeiras aparições do termo "educação Inclusiva", para Kassar (2011, p.71) "sob o impacto desses documentos e dentro de um conjunto de políticas sociais, um discurso de "educação inclusiva" toma corpo no país, de modo que profissionais que atuavam na Educação Especial passam, pouco a pouco, a utilizar o termo "inclusão" no lugar da bandeira da "integração".

Neste contexto, pode-se perceber o avanço no que se refere a inserção do aluno com deficiência na sala regular, desse modo, tentando diminuir barreiras e tentar assegurar o direito de acesso à educação igualitária.

Por outro lado, não adianta apenas "incluir" este aluno na sala de aula regular, sem que possa lhes ser oferecido condições mínimas para que o estudante com deficiência possa acompanhar, mesmo com suas limitações, as atividades pospostas na sala regular.

Em relação ao AEE para alunos com DI é recomendado discutir "os conteúdos advindos da sua própria experiência, segundo seus desejos, necessidades e capacidades. O exercício da atividade cognitiva ocorrerá a partir desses conteúdos" (BATISTA, 2006, p. 20).

Desse modo, entende-se que para promover condições para garantir maior interação dos alunos com os conteúdos abordados na sala regular precisa ser algo que eles gostem, algo que vivencie no seu cotidiano e lhes desperte o interesse.

É interessante que o professor conheça seus alunos, sua história, sua origem e particularidades podendo desenvolver e construir atividades envolvidas com o contexto dos estudantes e contribuir na sua construção enquanto sujeito para que possa contribuir nas ações destes alunos. 


\section{Deficiência Intelectual - DI}

O termo Deficiência Intelectual teve várias mudanças ao longo da história como por exemplo: "Cretinos, idiotas ou imbecis, retardados, doente mental, débil mental excepcional, entre outros". Termos científicos que eram utilizados para se retratar a Pessoa com Deficiência Intelectual (LAGO, 2010, p.39).

Segundo Lago (2010) o termo Deficiência Intelectual aparece como uma substituição do termo "deficiência mental" e "retardo mental" e que a definição esta foi aprovada pela organização mundial de saúde - OMS em 2004.

Mendes, Tannús-Valadão e Milanesi (2016, p.49) apontam que essa mudança de nomenclatura foi uma reivindicação dos próprios indivíduos "enquadradas nessa condição e pelo fato do termo "Deficiência Intelectual" ser cientificamente mais preciso, menos ofensivo e demonstrar mais respeito e dignidade para com as pessoas enquadradas nessa condição.

Lago (2010, p.42) ainda ressalta que a Associação Americana de Deficiência Intelectual e Desenvolvimento - AAIDD adota o termo Deficiência Intelectual sendo caracterizada "por um funcionamento intelectual inferior à média associado a limitações adaptativas em pelo menos duas áreas de habilidades e se manifesta antes dos 18 anos de idade".

Segundo Aranha (2003), umas das questões relacionadas ao funcionamento intelectual inferior à média estão relacionadas aos: cuidados pessoais; habilidades sociais; desempenho na família e comunidade, independência na locomoção, saúde e segurança, desempenho escolar, lazer e trabalho.

Existem muitos motivos que estão relacionados a Deficiência Intelectual, Silva (2014) aposta alguns dos motivos que estão relacionados a essa deficiência:

As causas da deficiência intelectual variam e são complexas, englobando, entre outros, fatores genéticos, como a Síndrome de Down, e ambientais, como decorrentes de infecções e do uso de drogas na gravidez, dificuldades no parto, prematuridade, meningite e traumas cranianos. De acordo com a Organização Mundial de Saúde (OMS), cerca de $5 \%$ da população mundial tem deficiência Intelectual. (SILVA, 2014, p.68)

Diante deste cenário, é importante que os professores conheçam seus alunos, tenham acesso aos seus respectivos laudos para que possam conhecer um pouco sobre o tipo de deficiência e que estratégias podem ser aplicadas para poder criar condições que possam contribuir no processo de aprendizagem deste sujeito.

\section{Modelagem matemática}

Na Educação Matemática, a modelagem é descrita e definida por vários aspectos e visões de acordo com alguns pesquisadores e estudiosos na área da educação (BARBOSA, 
2004; ALMEIDA E DIAS, 2004; BASSANEZI, 2010; BIEMBENGUT, 2014; SILVA, BORSSOI E FERRUZZI, 2017). Para Barbosa (2004) A modelagem é considerada um ambiente de aprendizagem onde os alunos são convidados a participar de alguma investigação, por meio da matemática, algum assunto da realidade; Almeida e Dias (2004, pg. 4), compreendem a modelagem como "uma atividade essencialmente cooperativa, onde a cooperação e a interação entre os alunos e entre professor e aluno têm um papel importante na construção do conhecimento". Para Silva; Borssoi e Ferruzzi (2017, p.24) a modelagem "é orientada pela busca de solução para um problema cuja origem se encontra fora do âmbito matemático". Para Bassanezi (2010, p.24), a modelagem matemática é vista como um:

... processo dinâmico utilizado para a obtenção e validação de modelos matemáticos. É uma forma de abstração e generalização com a finalidade de previsão de tendências. A modelagem consiste, na arte de transformar situações da realidade em problemas matemáticos cujas soluções devem ser interpretadas na linguagem usual.

Ao se usar a modelagem no campo educacional, segundo Bassanezi (2010, p.16) pode facilitar o entendimento dos conteúdos por parte dos educandos, pois a modelagem "facilita a combinação de aspectos lúdicos da matemática com seu potencial de aplicações”

O autor utiliza o termo "modelo" como uma forma de poder representar uma parte da realidade de algo que esteja sendo observado, como esta palavra "modelo" possui outras usualidades, ele se limita a dois tipos de modelos: Modelo Objeto que é caracterizado pela "representação de um objeto ou fato concreto; suas características predominantes são homogeneidade das variáveis" e o Modelo Teórico descrito como "aquele vinculado a uma teoria geral existente - será sempre construído em torno de um modelo objeto com um código de interpretação”. Na sequência, o autor define Modelo Matemático como “...um conjunto de símbolos e relações matemáticas que representam de alguma forma um objeto estudado" (BASSANEZI (2010, p.19-20).

Assim, um modelo matemático pode ser entendido como uma representação final de um objeto estudado durante um processo de pesquisa/investigação realizada por um grupo de pessoas, esse modelo pode aparecer em forma de construções protótipos, tabelas, gráficos, cartazes, maquetes, dentre outros. Bassanezi (2010) preconiza que esse modelo deve ser objetivo, apresentar uma linguagem concisa de modo a expressar as ideias e conclusões obtidas de maneiras claras e concretas.

Nesse sentido, o autor ainda completa que ao se trabalhar com a modelagem é extremamente necessário que todo o processo esteja sempre em aproximação com a realidade estudada. Além disso, é necessário saber que nem sempre será possível se trabalhar com a modelagem, sempre haverá restrições em que não será possível utilizar a modelagem 
matemática como estratégia, pois o ideal é que o uso da modelagem seja para contribuir com o desenvolvimento e compreensão do evento estudado.

Modelagem é o processo envolvido na elaboração de modelo de qualquer área do conhecimento. Trata-se de um processo de pesquisa. A essência desse processo emerge na mente de uma pessoa quando alguma dúvida genuína e/ou circunstância instigam-na a encontrar melhor forma para alcançar uma solução, descobrir meio para compreender, solucionar, alterar, ou ainda, criar ou aprimorar algo. Nesses termos, o modelo é expresso por meio de desenho ou imagem, projeto, esquema, gráfico, lei matemática, dentre outras formas (BIEMBENGUT, 2014, p. 201).

Logo, entende-se a modelagem como um método de ensino que tem como finalidade chegar a um modelo, para isso, é necessário, por meio de um tema gerador, identificar um problema, desenvolver um estudo e pesquisas, levantamento sobre essa temática discutida e na sequência tentar encontrar uma solução para esse problema levantado ou até mesmo sugestão, alteração ou aperfeiçoamento no mesmo. Assim, esse modelo pode ser expresso por meio de um protótipo, imagens, maquetes, gráficos, cartazes, dentre outros modos.

Biembengut $(2014 ; 2016)$, aponta que para se modelar um problema é necessário que seja pensado em três fases para que se alcance o modelo final em que se pretende chegar com a elaboração desse método de estudo, que são elas: Percepção e apreensão; Compreensão e explicitação; Significação e expressão.

Na percepção a apreensão, segundo Biembengut (2016), é o estágio de captação de ideias, de conhecer melhor sobre o tema estudado, se envolver com as questões levantadas. $\mathrm{O}$ tema é apresentado aos alunos com o objetivo de levá-los a investigação, levantar questões, pensar em questões norteadoras do tema gerado, ou seja, buscar dados gerais relacionados com o tema que será modelado (BIEMBENGUT, 2014).

Na fase da compreensão e explicitação, Biembengut (2016) nos aponta que esta é a fase mais desafiadora, já que é nesta fase que será feita a organização das ideias geradas, as hipóteses levantadas. Logo, quanto mais precisa for essa fase, melhor será para poder explicitar o problema levantado ao final da atividade. Nessa fase que os conteúdos curriculares geralmente aparecem para poder contribuir na elaboração do modelo final.

A fase da significação e expressão é o destinado para poder compreender o modelo expresso, é nesta fase que o modelo será verificado/avaliado, durante esta etapa é interessante que o modelo seja apresentado, analisado e justificado para poder observar sua validade. (BIEMBENGUT, 2016).

Desse modo, os alunos devem verificar o modelo apresentado, fazer testes, investigações, suposições em seguida avaliar o quão é válido ou se é valido o modelo apresentado, se precisa de adaptações ou se contempla a situação problema levantada. 
Nesta pesquisa, adotou-se a modelagem na perspectiva de Bassanezi (2010) e Biembengut (2014), porém será dado maior destaque nas discussões de Biembengut (2014) por se tratar de reflexões que perpassam por todo nível de ensino, desde a educação infantil até os cursos de formação continuada.

\section{Aspectos metodológicos}

A presente pesquisa apresenta uma abordagem qualitativa, por concordar com Lüdke e André (1986) quando afirmam que uma pesquisa qualitativa supõe contato direto do pesquisador com o ambiente ou objeto estudado. Além disso, a pesquisa faz uso do mapeamento na pesquisa educacional como preconiza Biembengut (2008, p.2), permitindo melhor entendimento sobre as ações pedagógicas com o intuito de "identificar e reconhecer traços constantes frente ao tempo, ao espaço, à formação, dentre outros”.

A autora ainda completa afirmando que pesquisa utilizando o mapeamento como recurso metodológico:

consiste em identificar e reconhecer o campo em que o objeto está inserido: identificação de entes (pessoas, coisas, objetos), fontes, caminhos a serem percorridos, sequências de ações ou etapas no processo de pesquisa e reconhecimento da origem, da natureza e das características dos dados que serão a estrutura da descrição e da explicação do fenômeno ou da questão (BIEMBENGUT, 2008, p. 79).

Os dados desta pesquisa foram obtidos por meio da seleção de 240 trabalhos encontrados na plataforma do Banco de Teses e Dissertações da Coordenação de Aperfeiçoamento de Pessoal de Nível Superior (CAPES), nos últimos cinco anos. A escolha por esse intervalo de tempo se dá pelo fato de serem produções mais recentes conforme recomenda Biembengut (2008).

Foi utilizado como busca no Banco de Teses e Dissertações os descritores "Modelagem Matemática" e "Deficiência Intelectual" com o intuito de ser apresentado os trabalhos que se aproxima desta temática. Além disso, foi realizado alguns filtros para poder afunilar mais os trabalhos, foram utilizados os seguintes filtros conforme o quadro a seguir:

Quadro 2: Filtros utilizados na seleção dos trabalhos analisados

\begin{tabular}{|l|l|}
\hline \multicolumn{1}{|c|}{ Tipo de Filtro } & \multicolumn{1}{c|}{ Quantidades de trabalho } \\
\hline Tipo & Doutorado (63), Mestrado (126) Mestrado Profissional (51). \\
\hline Ano & 2014, 2015, 2016, 2017, 2018. \\
\hline Grande área do conhecimento & Ciências exatas e da terra (48), Ciências humanas (192). \\
\hline Área do conhecimento & Educação (152), Educação Especial (40), Matemática (48). \\
\hline No item Área de avaliação & Educação (192), Matemática / Probabilidade E Estatística (48). \\
\hline Área de concentração & $\begin{array}{l}\text { Educação (8) Educação Brasileira (13), Educação do Indivíduo } \\
\text { Especial (40), Educação nas Ciências (2), Educação (124), Educação } \\
\text { Brasileira (2), Formação Docente para a Educação Básica (2), } \\
\text { Matemática (48), Práticas Educativas (1). }\end{array}$ \\
\hline
\end{tabular}

Fonte: Autores do trabalho 
Feito essa seleção, foram realizados a leitura dos títulos dos trabalhos com o objetivo de analisar quais se aproximavam da modelagem matemática como estratégia de ensino voltada para pessoas com deficiência Intelectual. Dos 240 trabalhos encontrados entre teses e dissertações (acadêmico e profissional), cinco foram selecionados, ao qual foram lidos e analisados com o intuito de investigar de que modo são apresentados esses trabalhos que versam sobre a Modelagem Matemática como método de ensino para pessoas com Deficiência Intelectual no contexto inclusivo.

Para melhorar o entendimento dos trabalhos analisados criou-se categorias a fim de compreender com mais facilidade as obras consultadas. Pois Biembengut (2008, p.09) afirma que para melhor interpretar os quesitos relevantes sobre dado fenômeno estudado o pesquisador precisa “...formular hipóteses verificáveis, variar as observações e as medidas e decidir em que medida este ente ou fenômeno sofre ou sofreu transformação [...]Para avaliar é preciso estabelecer categorias com princípios para efetuar uma análise mais fidedigna possível”. Desse modo, foram elencadas as seguintes categorias: i) Objetivos ou questões norteadoras das pesquisas; ii) Aportes teóricos das pesquisas; iii) Metodologias utilizadas; iv) Resultados e discussões; Na sequência será apresentado a análise de dados que consta baseado nos trabalhos analisados.

\section{Discussões e resultados}

Após feitos os filtros, foram encontrados cinco trabalhos que poderiam se aproximar da temática pesquisada (Modelagem matemática e Deficiência Intelectual). Serão utilizadas as terminologias D1, D2, D3, D4 e D5 para se referir as Dissertações conforme apresentadas no quadro a seguir em ordem cronológica de anos apresentados.

Quadro 1: Relação dos trabalhos encontrados usando as buscas "Modelagem Matemática" e

\begin{tabular}{|l|l|l|l|l|}
\hline Tipo & \multicolumn{1}{|c|}{ "Deficiência Intelectual” } & \multicolumn{1}{|c|}{ Autor } & \multicolumn{1}{|c|}{ Instituição } & Ano \\
\hline D1 & $\begin{array}{l}\text { O uso de jogos do software educativo Hércules e Jiló } \\
\text { no mundo da matemática na construção do conceito } \\
\text { de número por estudantes com deficiência intelectual }\end{array}$ & $\begin{array}{l}\text { Cristiane } \\
\text { Ferreira Rolim }\end{array}$ & $\begin{array}{l}\text { Universidade } \\
\text { de Brasília }\end{array}$ & 2015 \\
\hline D2 & $\begin{array}{l}\text { A prática pedagógica de professoras de uma aluna } \\
\text { com deficiência intelectual: desafios e possibilidades } \\
\text { no cotidiano de uma escola de ensino fundamental }\end{array}$ & $\begin{array}{l}\text { Raquel } \\
\text { Almeida Costa }\end{array}$ & $\begin{array}{l}\text { Universidade } \\
\text { Federal de } \\
\text { Uberlândia }\end{array}$ & 2016 \\
\hline D3 & $\begin{array}{l}\text { A construção do número pela criança com deficiência } \\
\text { intelectual: a percepção entre diferentes ambientes } \\
\text { escolares }\end{array}$ & $\begin{array}{l}\text { Carine } \\
\text { Almeida Silva } \\
\text { Desenvolvimento do pensamento algébrico em alunos } \\
\text { deficiência intelectual no atendimento } \\
\text { educacional especializado na perspectiva histórico- } \\
\text { cultural }\end{array}$ & $\begin{array}{l}\text { Universidade } \\
\text { de Brasília }\end{array}$ & 2017 \\
\hline D4riela Maria & $\begin{array}{l}\text { Noronha } \\
\text { Regional do } \\
\text { Noroeste } \\
\text { Estado do Rio } \\
\text { Grande do Sul }\end{array}$ & 2017 \\
\hline D5 & $\begin{array}{l}\text { A prática do xadrez no contexto escolar e a } \\
\text { aprendizagem de alunos com deficiência intelectual }\end{array}$ & $\begin{array}{l}\text { Euripedes } \\
\text { Rodrigues das } \\
\text { Neves }\end{array}$ & $\begin{array}{l}\text { Universidade } \\
\text { de Brasília }\end{array}$ & 2017 \\
\hline
\end{tabular}

Fonte: Autores do trabalho.

ISSN 2526-2882 
Foi levado em consideração os trabalhos que trouxeram em seu título o termo Deficiência Intelectual relacionado com a matemática, exceto o D2 que trouxe em seu título, além da Deficiência Intelectual questões relacionadas as práticas pedagógicas, nesse sentido, foi selecionado com o intuito de verificar se a modelagem matemática poderia está sendo mencionada. Na sequência esses trabalhos foram lidos para verificar se a Modelagem Matemática se encontrava presentes nestas pesquisas conforme descritos nas categorias a seguir:

i) Objetivos ou questões norteadoras das pesquisas. Na D1,Cristiane Ferreira Rolim, defendida em 2015 apresenta como objetivo geral analisar o uso de jogos do software educativo Hércules e Jiló no mundo da matemáticana construção do conceito de número por estudantes com deficiência intelectual no início de escolarização, de uma Classe Especial da Rede Pública de Ensino do Distrito Federal, a D2 de Raquel Almeida Costa defendida em 2016 teve por objetivo conhecer e analisar as práticas pedagógicas desenvolvidas no processo de ensinoaprendizagem de alunas com Deficiência Intelectual (DI), matriculadas em uma classe comum de ensino fundamental I, na D3 de autoria de Carine Almeida Silva, defendida em 2017 foi levantado o seguinte objetivo de analisar os processos mentais associados à construção do número desenvolvidos na sala de aula e na sala de recursos por uma criança com deficiência intelectual em fase de alfabetização; A D4 de autoria de Adriela Maria Noronha que teve sua defesa em 2017 apresentou como objetivo identificar elementos que potencializam a aprendizagem conceitual de alunos com deficiência intelectual a partir da proposição de situações matemáticas durante o AEE-Atendimento Educacional Especializado e pôr fim a D5 de autoria de Eurípedes Rodrigues das Neves que traz o objetivo de investigar se o uso do xadrez auxilia na aprendizagem do aluno com deficiência intelectual dos Anos Finais do Ensino Fundamental.

Desse modo, é possível perceber que os trabalhos objetivam discussões adversas sobre Deficiência intelectual, porém, não é possível notar a utilização da Modelagem matemática como estratégia de ensino nestes contextos.

ii) Aportes teóricos das pesquisas. A D1 apresenta em sua fundamentação teórica um estudo sobre a história da educação especial, na sequência caracterizando Deficiência Intelectual, traz pesquisas que falam sobre o jogo na construção do conhecimento sobre o uso das tecnologias e dos computadores na educação bem como as tecnologias aplicadas à educação especial.

Na D2 é apresentado questões relacionadas aos educandos com deficiência intelectual e apresentam o processo/percurso conceitual sobre o termo Deficiência Intelectual. Na sequência apresenta pressupostos de desenvolvimento e aprendizagem para pessoas com DI na perspectiva de Vygotsky além das políticas públicas voltadas para pessoa com deficiência. 
A D3 a autora traz discursos referente ao movimento da Educação Matemática no mundo e no Brasil, em seguida o cenário sobre a educação inclusiva no Distrito federal em especial sobre a DI. Apresenta também estudos de Danyluk (1998) (referente a construção do número e alfabetização matemática, Piaget (1981) e Kamii (2012) referente ao conceito de número e construções feitas pelas crianças, a Teoria dos Campos Conceituais de Vergnaud (1990, 1993, 2003, 2009) e nos estudos de Vigotsky (1983, 1997, 2003, 2004, 2009, 2011) sobre a perspectiva histórico cultural.

No que se refere a D4, a autora traz discursos sobre o Atendimento Educacional Especializado - AEE para alunos com Deficiência Intelectual. Na sequência é exposto as contribuições de Vigotsky Leontiev referente a perspectiva Histórico-Cultural e contribuições das pesquisas sobre apropriação de conceitos matemáticos por alunos com Deficiência Intelectual.

No que se refere a D5, o autor aborda os documentos oficiais e entidades como AAIDD - American Associationon Intellectual and Developmental Disabilities que definem Deficiência Intelectual, além disso, traz algumas contribuições de autores que falam de aprendizagem como Vygotsky e Maia, e raciocínio lógico segundo Haak, Murcho e Priest e as contribuições dos jogos no processo de aprendizagem.

Neste sentido, não foi possível verificar nos trabalhos apresentados a Modelagem matemática como método científico da pesquisa.

iii) Metodologias utilizadas: Referente ao método utilizado foi verificado em os trabalhos (D1, D2, D3, D4 e D5) utilizaram uma abordagem de cunho qualitativo, além disso, todas elas utilizaram o estudo de caso em suas pesquisas, exceto a D5 que teve um cunho fenomenológico e empírico com enfoque na pesquisa-ação. Nessa pesquisa o autor infere que teve participação nas ações desenvolvida e atuou com grande número de sujeitos nas atividades.

Desse modo, nota-se que os trabalhos verificados utilizaram em suas pesquisas métodos de estudo de caso como estratégia de pesquisa. Logo, acredita-se que é preciso dispor de mais pesquisas que utilizam outros métodos que possam contribuir no que se refere ao processo de ensino-aprendizagem para o indivíduo com Deficiência Intelectual.

iv) Resultados e discussões: Na D1, a autora afirma que foi possível constatar que os jogos propostos pelo Software Hércules e Jiló no Mundo da Matemática, foram capazes de instigar o estudante a um processo mais criativo e motivador, em relação às aprendizagens relacionadas aos conteúdos de matemática, assim como despertar a professora para a contribuição que as tecnologias podem oferecer, quando utilizado de forma intencionada no processo de ensino e aprendizagem dos estudantes.

O estudo desenvolvido pela D2 revela uma necessidade dos docentes reverem algumas de suas ações efetuadas, com a intenção de desenvolver práticas pedagógicas mais 
democráticas de ensino de modo a estimular as interações entre os alunos, além do sistema de ensino investir e incentivar na qualificação dos docentes no tocante a educação inclusiva.

Já com a D3 os resultados foram apresentados em categorias de análise de modo que a criança, sujeito de pesquisa, demonstra simbolizar os dois ambientes escolares diferentemente, é capaz de resgatar sua autoconfiança em sua capacidade de aprendizagem e realiza importantes avanços na construção do conceito de número. As análises apontam para o resgate, pela criança, de seu lugar como sujeito de suas aprendizagens e de seu desenvolvimento

A D4 traz como resultados que a interdependência entre as atividades principais do professor - atividade de ensino e do aluno - atividade de estudo, impulsiona a formação e a transformação do psiquismo do aluno e do professor. Apontam, que a qualidade das interações entre alunos e professor em situações de estudo no AEE favorece o processo de significação algébrica, e que o ambiente interativo propicia a imitação do outro impulsionando a apropriação dos significados conceituais. E, indicam que a apropriação do pensamento algébrico por alunos com deficiência intelectual potencializa o desenvolvimento conceitual.

Finalizando com a D5 o autor pode perceber que, ao utilizar procedimentos didáticopedagógicos adequados e orientações-guia, os discentes desenvolveram habilidades ao jogar xadrez, tanto no contexto escolar quanto fora dele, articulando e utilizando táticas, envolvendo a exploração do raciocínio, na ação de aprender e jogar xadrez em nível principiante. Habilidades, aprendizagens cognitivas e sócio afetivas foram atestadas nas entrevistas e por meio de observações do pesquisador: a elevação da autoestima, a melhoria das relações interpessoais e sociais e a capacidade de tomar decisões, seja relacionado ao presente ou ações que conduziriam ao futuro, ao desejar ter uma vida com identidade e uma história construída a partir de si como arquiteto ou capitão do seu destino.

\section{Conclusões}

O presente artigo teve por objetivo investigar de que maneira são apresentados os trabalhos que versam sobre a Modelagem Matemática como estratégia de ensino para pessoas com Deficiência Intelectual no contexto inclusivo. Para isto foi usado o mapeamento como princípio metodológico desse trabalho conforme Biembengut (2008). Foram selecionados Teses e Dissertações disponíveis no Banco de Teses e Dissertações da Coordenação de Aperfeiçoamento de Pessoal de Nível Superior (CAPES) como material de consulta.

Durante as buscas foram consultados primeiramente os trabalhos que relacionaram a Deficiência Intelectual e a matemática e na sequência observar se esses trabalhos traziam a modelagem como estratégia de ensino.

Percebe-se que poucas pesquisas foram apresentadas trazendo a Deficiência Intelectual voltado para o ensino de matemática. E isto é preocupante já que $5 \%$ da população 
mundial, segundo a Organização Mundial de Saúde - OMS possui deficiência Intelectual. E o maior tipo de deficiência entre o Público Alvo da Educação Especial. Logo, o professor poderá encontrar com mais facilidade alunos com Deficiência Intelectual em sua sala, e este, precisa ter acesso a mais estudos e pesquisas voltadas para este público.

No que consiste a educação inclusiva voltada para Deficientes Intelectuais foi possível perceber que é possível promover a inclusão destes sujeitos no contexto na sala regular, no entanto, é necessário que o professor tenha condições e interesse para poder adaptar suas aulas para esse público, que esse aluno tenha acesso ao Atendimento Educacional Especializado para que possa contribuir na sua formação e vivência, que os professores procurem sempre atividades que contemplem a realidade destes estudantes e que seja investido e incentivado na formação do professor para educação inclusiva.

Foi possível perceber que em nenhum dos trabalhos analisados houve a utilização da Modelagem Matemática com estratégia de ensino pensando no estudante com Deficiência Intelectual no contexto da inclusão. Foi possível perceber em alguns trabalhos que a Modelagem Matemática, ou algumas de suas etapas, pode até aparecer de forma implícita no desenvolvimento dos trabalhos, porém, não foi descrita como modelagem pelo autor da obra.

Salienta-se que é possível que tenha outros trabalhos que possa trazer a Modelagem Matemática como estratégia de ensino voltado para o aluno com Deficiência Intelectual. Ou até mesmo, trabalhos que foi realizado numa turma regular que possuía aluno com Deficiência Intelectual de modo que esse público não seja o foco do trabalho, no entanto, não foi encontrado nenhum destes casos nas buscas realizadas por este estudo.

Como pesquisas futuras, é interessante fazer uso da Modelagem Matemática como estratégia de ensino para o aluno com Deficiência Intelectual no contexto da inclusão, ou seja, analisar o aprendizado deste aluno no contexto da sala regular com os demais colegas, avaliar seu aprendizado nas atividades propostas.

\section{Referências}

BRASIL. Presidência da República. Casa Civil. Subchefia para Assuntos Jurídicos. Lei 9.394, de 20 de dezembro de 1996. Estabelece as diretrizes e bases da educação nacional. Brasília, $\mathrm{DF}$, 1996.

Disponível em: http://www.planalto.gov.br/ccivil_03/leis/L9394.htm. Acesso em: 27 abr. 2019.

BRASIL. Presidência da República. Casa Civil. Subchefia para Assuntos Jurídicos. Decreto 7611, de 17 de novembro de 2o11. Revoga o Decreto 6.571, de 17 de setembro de 2008. Dispõe sobre a educação especial, o atendimento educacional especializado e dá outras providências. Brasília, DF, 2011. Disponível em: http://www.planalto.gov.br/ccivil_03/_ato2011-2014/2011/decreto/d7611.htm. Acesso em: 13 maio 2019. 
BRASIL. Ministério da Educação. Plano decenal de educação para todos. Brasília, DF, 1993. Disponível em: http://www.dominiopublico.gov.br/download/texto/meo01523.pdf Acesso em: 25 abr. 2019.

ALMEIDA, L. M. W.; DIAS, M. R. Um estudo sobre o uso da modelagem matemática comoestratégia de ensino e aprendizagem. Bolema. Boletim de Educação Matemática (UNESP. RioClaro. Impresso), Rio Claro, v. ano 17, n. 22, p. 19-36, 2004.

ARANHA, M. S. F. Estratégias para a educação de alunos com necessidades educacionais especiais. Brasília: Ministério da Educação, Secretaria de Educação Especial, 2003.

BARBOSA, J.C. (2004). Modelagem Matemática: O que é? Por que? Como? In Veritati. n. 4, 73-80.

BASSANESI, R. C. Ensino-aprendizagem com modelagem matemática: uma nova estratégia. 3. Ed., $2^{\text {a }}$ reimpressão. São Paulo: Contexto, 2010.

BATISTA, C. A. M. Educação inclusiva: atendimento educacional especializado para a deficiência mental. [2. ed.] / Cristina Abranches Mota Batista, Maria Teresa EglerMantoan. -Brasília: MEC, SEESP, 2006. 68 p.

BIEMBENGUT, M.S. Mapeamento como princípio metodológico para pesquisa educacional. In: MACHADO, N. J. \& CUNHA, M. O. (Orgs.). Linguagem, conhecimento e ação: ensaios de epistemologia e didática. São Paulo: Escrituras,2003. p. 1-11

BIEmbengut, M. S. Mapeamento na Pesquisa Educacional. Rio de Janeiro: Editora Ciência Moderna, 2008.

BIEMbengut, M. S. Modelagem na Educação Matemática e na Ciência. 1. ed. São Paulo: Editora Livraria da Física, 2016. v. 1. 367p .

BIEMBENGUT, Maria Salett. Modelagem Matemática \& Resolução de Problemas, Projetos e Etnomatemática: Pontos Confluentes. ALEXANDRIA Revista de Educação em Ciência e Tecnologia, v. 7, n. 2, p. 197-219, nov. 2014.

LAGO, D. C. Atendimento Educacional Especializado para alunos com deficiência intelectual baseado no coensino em dois municípios. 2014. 270f. Tese (Doutorado em Educação Especial). Programa de Pós-Graduação em Educação Especial, Universidade Federal de São Carlos, São Carlos, 2014.

KASSAR, M. C. M. Educação Especial na perspectiva da educação inclusiva: desafios da implantação de uma política nacional. Educar em Revista, Curitiba, n. 41, set. 2011.

LÜDKE, M.; ANDRÉ, M. E. D. A. Pesquisa em Educação: Abordagens Qualitativas. São Paulo: Editora Pedagógica e Universitária Ltda. São Paulo, 1996.

MENDES, E. Z.; TANNÚS-VALADÃO, G.; MILANESI, J. B. Atendimento educacional especializado para estudante com deficiência intelectual: os diferentes discursos dos 
professores especializados sobre o que e como ensinar. Revista Linhas. Florianópolis, v. 17, n. 35, p. 45-67, set./dez. 2016.

MENDES, E. G.; ALMEIDA, M. A.; TOYODA, C. Y. Inclusão escolar pela via da colaboração entre educação especial e educação regular. Educar em Revista, Curitiba, v.41, n.1, p.81-93, 2011.

MILANEZ, S.G.C. (Org.); OLIVEIRA, A. A. S. (Org.); MISQUIATTI, A. R. N. (Org.). Atendimento Educacional Especializado para alunos com deficiência intelectual e transtornos globais do desenvolvimento. $1^{\text {a }}$. ed. São Paulo; Marília: Cultura Acadêmica; Oficina Universitária, 2013. 142p

SILVA, L. G. dos S. Educação Inclusiva; Práticas para uma escola sem Exclusões. /Luiza Guaciara dos Santos Silva. - 1. Ed. - São Paulo: Paulinas, 2014. - (Coleção pedagogia e educação).

SILVA, K. A. P.; BORSSOI, A. H.; FERRUZZI, E. C. Modelagem matemática: uma atividade desencadeadora de tarefas. BOLETIM ONLINE DE EDUCAÇÃo MATEMÁTICA, v. 5, p. 122-140, 2017.

\section{Biografia Resumida}

Edmilson Ferreira Pereira Junior: Licenciado em Matemática pela Universidade Federal do Recôncavo da Bahia. Mestre em Educação Matemática pela Universidade Estadual de Santa Cruz (UESC). Professor da Secretária Estadual de Educação da Bahia - SEC no Centro Educacional de Educação Profissional em Alimentos e Recursos Naturais Pio XII. Membro do Grupo de pesquisa Educação Matemática e Diversidade Cultural (GPEMDiC).

Lattes: http://lattes.cnpq.br/5349403514029511

Contato: edmilsonufrb@gmail.com

Jurema Lindote Botelho Peixoto: Licenciada em Matemática pela Universidade Estadual de Santa Cruz. Mestre em Matemática pela Universidade Federal da Bahia (UFBA). Doutora em Difusão do Conhecimento pela Universidade Federal da Bahia (UFBA). Professora Adjunta da Universidade de Santa Cruz (UESC-BA), docente do programa de Pós-Graduação em Educação Matemática da UESC; Líder do grupo de Pesquisa Educação Matemática e Diversidade Cultural- GEPEMDiC. Membro do ISSN 2526-2882 
Grupo de pesquisa Grupo de Estudos e Pesquisas em Educação Inclusiva - GEPEI.

Lattes: http://lattes.cnpq.br/o900970451569924

Contato: jurema@uesc.br 